\title{
Transition from Hospital to Home: Can Pharmacists' Interventions Improve Patients' Outcomes?
}

\author{
Lalitha Raman-Wilms
}

$\mathrm{I}^{\mathrm{n}}$ a 2004 study conducted in Canada, Forster and others $^{1}$ found that more than 1 in 5 patients discharged from a general medicine service to home experienced an adverse event, and $72 \%$ of the adverse events were related to medications. Other authors have reported similar findings, with adverse drug events being common in the month following discharge. ${ }^{2}$ In a recent small Canadian study, ${ }^{3} 77 \%$ of patients discharged from an acute care institution had at least one drug therapy problem in the 2 weeks following discharge, linked to gaps in the transfer of medication-related information. The authors of many of these studies have suggested that close follow-up in the first few weeks after discharge could prevent many of these adverse drug events, improving patient outcomes and minimizing the expenditure of health care resources.

Intuitively, it seems that patients would benefit from care provided by a pharmacist during this transition period. In this issue of the Journal, Flanagan and others ${ }^{4}$ describe a clinical program in which elderly patients received medication management services in their homes after discharge from hospital, with savings in health service resources during the following year. Although many studies have reported positive outcomes from provision of pharmacists' services in the home, many more have indicated otherwise, including randomized controlled trials $s^{5}$ that have demonstrated an increase in hospital admissions among patients receiving such in-home care. One suggestion has been that these results may be due to better awareness of health concerns, leading to use of more resources, ${ }^{5}$ but other issues need to be considered.

Factors that may account for the conflicting evidence in this area include the type of intervention studied, the pharmacist's qualifications, and whether or not the care was provided within a collaborative context.

Studies evaluating clinical pharmacy services in the home have been published over a period of more than 3 decades. During this time, the role of the pharmacist has changed considerably. Earlier literature reflected the pharmacist's role as a consultant within established home care agencies. The pharmacist did not often work directly with the patient but instead provided information to the home care team, with a focus on medication counselling. More recently, pharmacists' services have been offered as an extension of primary care, separate from other services that the patient may receive, with a focus on medication reviews. As a consequence of this shift over

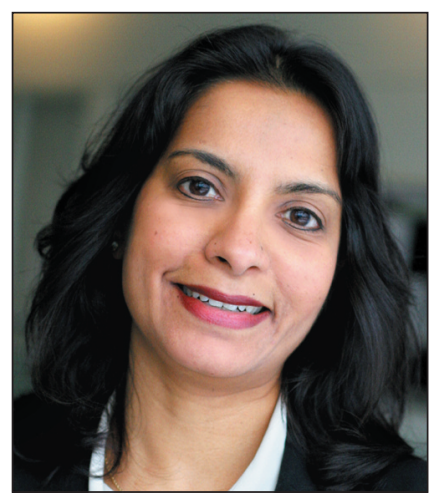
time, the studies reflect the heterogeneity of pharmacists' interventions, making it difficult to compare results.

One evaluation of randomized controlled trials of pharmacist involvement in home care programs found a significant difference in the number of drug-related problems identified and the disease-specific patient health outcomes between intervention and control groups, with a few studies demonstrating a decrease in rates of hospital admission. ${ }^{6}$ Other studies have indicated that interventions focusing solely on patient education and adherence do not affect patient outcomes, such as rates of readmission to hospital. However, interventions that include a comprehensive medication management service, ${ }^{7}$ similar to that outlined by Flanagan and others, ${ }^{4}$ have yielded positive patient outcomes. Previous studies and reviews used a relatively broad definition of the term "medication management", ${ }^{6}$ but this term is more clearly defined today. Consistency in what the intervention entails and a common definition of medication management will provide a better basis for evaluations and comparisons of patients' outcomes and costs.

A second factor to consider is the difference in qualifications of the pharmacists providing care, with some studies providing enhanced training and others offering no additional training. For example, the government-funded Home Medicines Review program of Australia, ${ }^{8}$ which is offered to patients through physician referral, involves an accredited 
pharmacist performing a medication review to optimize the patient's drug therapy. This review includes formally discussing the plan with the physician and the patient, implementing the plan, and providing monitoring and follow-up. Similar to accredited pharmacists or experienced pharmacists who have undertaken a specific education program or examination, pharmacists working in hospitals often undergo specialized training, usually through a formal residency program. More recently, the experience of pharmacists working in primary care has highlighted the importance of a unique set of skills required to provide effective patient care in this setting. Analysis of these experiences has led to creation of the ADAPT program for pharmacists (Adapting Pharmacist Skills and Approaches to Maximize Patients' Drug Therapy Effectiveness). ${ }^{9}$ Similarly, pharmacists may require specialized training if they are to provide effective care in patients' homes.

One enabler allowing provision of pharmacists' services in the home, which is commonly cited in the literature, is an effective relationship between the physician and the pharmacist, as well as between the patient and the pharmacist. ${ }^{7}$ The findings of various studies have indicated that care provided in collaboration with other team members (often a physician working closely with a pharmacist or a nurse) results in better patient outcomes than care provided by one health care professional working alone. ${ }^{10}$ This highlights the importance of working collaboratively with both the patient and his or her health care team, since effective communication and collaboration between the pharmacist and other members of the interprofessional team are key to successful patient outcomes.

In their description of the medication management program, Flanagan and others ${ }^{4}$ highlight the importance of the pharmacist providing patient care in the home shortly after discharge from hospital. The problem of adverse events after discharge may be magnified in elderly patients, who typically have more comorbidities and are taking many more medications than younger patients. Given Canada's aging population, the importance of establishing programs for elderly patients who are being transferred from hospital to home and the role of these programs in minimizing adverse drug events and readmissions will only increase.

To achieve better patient outcomes and to generate a greater return on investment, consideration should be given to well-defined interventions (including a comprehensive medication management program), clear qualifications to provide home-based care, and close collaboration and communication with patients, physicians, and other members of the patient's health care team.

\section{References}

1. Forster AJ, Clark HJ, Menard A, Dupuis N, Chernish R, Chandok N, et al. Adverse events among medical patients after discharge from hospital. CMAJ 2004;170(3):345-349.

2. Gray SL, Mahoney JE, Blough DK. Adverse drug events in elderly patients receiving home health services following hospital discharge. Ann Pharmacother 1999;33(11):1147-1153.

3. Cameron K, Siu V, Marr P, Hamandi B, Fernandes O. Post-hospital discharge: medication discrepancies and drug therapy problems in primary care [abstract]. Can J Hosp Pharm 2010;63(1):72.

4. Flanagan P, Virani A, Baker W, Roelants H. Pharmacists making house calls: Innovative role or overkill? Can J Hosp Pharm 2010;63(6):412-419.

5. Holland R, Lenaghan E, Harvey I, Smith R, Shepstone L, Lipp A, et al. Does home based medication review keep older people out of hospital? The HOMER randomised controlled trial. BMJ 2005;330(7486):293.

6. MacKeigan LD, Nissen LM. Clinical pharmacy services in the home. Dis Manage Health Outcomes 2008;16(4):227-244.

7. Pellegrino AN, Martin MT, Tilton JJ, Touchette DR. Medication therapy management services — definitions and outcomes. Drugs 2009;69(4): 393-406.

8. Home medicines review (HMR). Adelaide: Australian Government, Medicare Australia; [updated 2010 Sep 2; cited 2010 Sep 9]. Available from: www.medicareaustralia.gov.au/provider/pbs/fourth-agreement/hmr.jsp

9. CPhA-CSHP Primary Care Pharmacy Specialty Network. ADAPT: adapting pharmacists' skills and approaches to maximize patients' drug therapy effectiveness. Ottawa (ON): Canadian Pharmacists Association and Canadian Society of Hospital Pharmacy; [cited 2010 Sep 9]. Available from: www.cshp.ca/productsServices/eob/546/Adapt.pdf

10. Walsh JM, McDonald KM, Shojania KG, Sundaram V, Nayak S, Lewis R, et al. Quality improvement strategies for hypertension management: a systematic review. Med Care 2006;44(7):646-657.

Lalitha Raman-Wilms, BSc(Phm), PharmD, FCSHP, is an Associate Professor and Director, Division of Pharmacy Practice, Leslie Dan Faculty of Pharmacy, University of Toronto, Toronto, Ontario. She is also an Associate Editor for the CJHP.

\section{Address correspondence to:}

Dr Lalitha Raman-Wilms

Leslie Dan Faculty of Pharmacy

University of Toronto

144 College Street

Toronto ON M5S 3M2

e-mail: I.raman.wilms@utoronto.ca 